\title{
Redearch Paper: The Relationship Between Reaction Time of Electrical Stapedius Reflex and Auditory Performance in Cochlear-implanted Children
}

\author{
Fatemeh Arbabi $^{1}$, Saeideh Mehrkian ${ }^{* *}$ (D), Hesamaldin Emamdjomeh² (D), Akbar Biglarian ${ }^{3}$ (D) \\ 1. Department of Audiology, University of Social Welfare and Rehabilitation Sciences, Tehran, Iran. \\ 2. ENT, Head and Neck Research Center, Iran University of Medical Sciences, Tehran, Iran. \\ 3. Department of Statistics, University of Social Welfare and Rehabilitation Sciences, Tehran, Iran.
}

\begin{tabular}{|c|c|}
\hline $\begin{array}{l}\text { Use your device to scan } \\
\text { and read the article online }\end{array}$ & Citation: Arbabi F, Mehrkian S, Emamdjomeh H, Biglarian A. The Relationship Between Reaction Time of Electrical Sta- \\
\hline 口firis: & $\begin{array}{l}\text { pedius Reflex and Auditory Performance in Cochlear-implanted Children. Iranian Rehabilitation Journal. 2021; 19(2):189-198. } \\
\text { http://dx.doi.org/10.32598/irj.19.2.1409.1 }\end{array}$ \\
\hline atstas & doi'http://dx.doi.org/10.32598/irj.19.2.1409.1 \\
\hline
\end{tabular}

Article info:

Received: 18 Apr 2021

Accepted: 20 Jun 2021

Available Online: 01 June 2021

\section{Keywords:}

Cochlear implantation, Electrical stapedius reflex reaction time, Auditory performance, Categories of Auditory Performance

\section{ABSTRACT}

Objectives: A common concern in some cochlear-implanted children is the lack of desired progress in auditory and listening skills. Such a concern remains despite proper verbal processor programming, additional disabilities, and continuous participation in hearing rehabilitation programs. A more detailed assessment of pathways and centers of the auditory processing at the lower end of the brain stem by measuring the time of the Electrical Stapedius Reflex (ESR), and investigating its relation to auditory perception skills can provide significant information about choosing the appropriate rehabilitation method.

Methods: In total, 20 unilateral cochlear-implanted children (3-7-year-olds) participated in this research. All of them were implanted for $\geq 2$ years and participated for $\geq 1$ year in the auditory-verbal rehabilitation program. The ESR reaction time was measured for 3 electrodes in the apex, middle, and basal areas. The Categories of Auditory Performance (CAP-II) test score was used to assess the progress of auditory skills. Then the correlation between CAP-II test score and ESR reaction time was investigated per each electrode.

Results: There was a significant inverse correlation between the ESR reaction time and the CAP II test scores in the apex electrodes $(\mathrm{r}=-0.5, \mathrm{P}<0.05)$. However, no such correlation was observed in the middle $(\mathrm{r}=0.34, \mathrm{P}>0.05)$ and basal $(\mathrm{r}=-0.06, \mathrm{P}>0.05)$ electrodes.

Discussion: There was a significant correlation between the shorter reaction time of ESR in the apex electrode and the higher scores in the CAP-II test for auditory skills in children. Therefore, examining the ESR reaction time can be useful for prediction of the benefits of cochlear implantation as well as choosing a better rehabilitation approach for cochlearimplanted children.

\section{"Corresponding Author:}

Saeideh Mehrkian, PhD.

Address: Department of Audiology, University of Social Welfare and Rehabilitation Sciences, Tehran, Iran

Tel: +98 (21) 22180066

E-mail: saeidehmehrkian@yahoo.com 


\section{Highlights}

- Not all deaf individuals benefit from the cochlear implant device in the same way.

- Several variables appear to critically affect post-implant auditory skills and linguistic performance.

- Electrical Stapedius Reflex (ESR) reaction time can be helpful in the prediction of the effectiveness of the cochlear implant in children.

\section{Plain Language Summary}

Cochlear implant recipients are widely varied in several clinical characteristics which are recognized to affect auditory performance with a cochlear implant. Nowadays, due to the lower age of the cochlear implant, there is a need for precise electrophysiological tools for proper programming of speech processor of the cochlear implant, as well as more accurate assessments of neural pathways involved in auditory processing, to predict the benefit of cochlear implantation and adoption of appropriate rehabilitation techniques. Since the stapedius reflex arc pathway involves part of the ventral and dorsal auditory stream, the study of the relationship between its parameters (by using ESR reaction time) and auditory perception in cochlear implant children can provide useful information for predicting their usefulness, proper programming of the device, and selecting appropriate rehabilitation program to improve their auditory skills.

\section{Introduction}

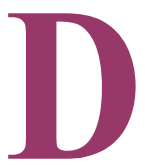

uring the last 25 years, Cochlear Implant (CI) has been used as an effective device of auditory rehabilitation for individuals with severe to profound hearing impairments. Successive developments in cochlear implantation during the recent decades empowered this population to substantially use cochlear implants. The advantages of using a CI can go beyond the awareness of environmental sounds, better quality of life, improved psychological wellbeing, and significant improvements in auditory perception [1]. In recent years, the technology and knowledge of CIs in Iran have witnessed major advances; increasingly, children with severe or profound sensorineural hearing loss have received CIs [2].

According to the literature, 3 out of 1000 neonates are born with sensorineural hearing loss [3]. The prevalence of neonatal hearing loss in Iran is comparable to developed and developing countries [4]. Since 1992, 11700 children and adults have undergone cochlear implantation. However, the lack of desired and appropriate progress in rehabilitation programs and the insufficient acquisition of optimal verbal and auditory skills are among the most frequent problems in CI users. For the following reasons, the variation in speech perception is predictable: CI provides an artificial, human-made sensation of hearing that is clearly different from normal hearing. Therefore, CI users have to familiarize themselves with and learn to process this unusual and degraded sound stimulation. The ability to do this varies between individuals and is a time-consuming process [5].

CI recipients widely varied in several clinical characteristics, i.e., recognized to affect auditory performance with a CI. These major characteristics are divided into 3 groups; preoperative, intraoperative, and postoperative classes. The relevant preoperative factors include the duration of deafness before $\mathrm{CI}$, the level of preoperative remaining usable hearing, and the history of hearing aid use. Moreover, intraoperative characteristics include the number of active electrodes, the position of electrode array within the cochlea, and the depth of electrode insertion $[1,6]$. Postoperative factors are device condition, fitting, and rehabilitation program. All of these factors are critical stages that should be considered in achieving the best results [5].

Children with severe and profound hearing loss are unaware of the loudness of the sounds and effective communication capability; thus, determining the correct auditory comfortable level and the electrical dynamic range of the CI device is difficult based on behavioral assessments. Considering the lower age of the CI, there is a need for precise electrophysiological tools for proper programming of the speech processor of CI [7]. Besides, more accurate assessments of neural pathways involved in auditory processing are required. Accordingly, such measures could help to predict the benefits of cochlear 
implantation and the adoption of appropriate rehabilitation techniques.

One of the objective electrophysiological assessments is the Electrical Stapedius Reflex Threshold (ESRT). The structures involved in the acoustic reflex arc are part of the ventral and dorsal stream of the central auditory processing in the lower end of the brainstem. The importance and role of subcortical structures in auditory processing are well understood [8]. The normal activity of the stapedius muscle reflex in response to the acoustic stimulation requires the health of the afferent and efferent pathways in the brainstem [9]. The Superior Olivary Complex (SOC) neurons play a common role in acoustic reflexes and some aspects of auditory processing [10]. Several clinical studies highlighted the possible involvement of auditory cortical areas in the acoustic reflex arc $[11,12]$.

ESRT has advantages over other electrophysiological assessments, such as Neuro Response Telemetry (NRT) and Electrical Auditory Brainstem Response (EABR). Compared to NRT, which only represents the auditory nerve response, ESRT examines more structures and pathways in the brain stem $[13,14]$. Likewise, in contrast to EABR, which only examines the afferent pathway of the nerve, ESRT examines the afferent and efferent neural pathways and provides a higher diagnostic value. Additionally, the neural reflex circuit receives inputs from the higher end of the brainstem and can reflect the effects of higher-level processing $[12,13]$. ESRT is easier and faster than other electrophysiological tests and requires no additional and expensive equipment. It can be easily recorded with the standard audiometric instruments $[14,15]$ and not affected by electrical stimulation artifacts. By direct observation or immittance measurements, ESRT can be intraoperatively obtained during CI surgery [15]. Moreover, unlike NRT or EABR, it can be synchronized with the same stimulus used for speech processor programming [12]. Importantly, for most patients, ESRT can be recorded around the comfort level and below the uncomfortable level [16]. Measurable parameters in ESR are threshold and reaction time; they can provide data to the auditory pathways of the lower end of the brainstem. The reflex threshold is the lowest stimulation level, which causes recordable deviation in the baseline. ESRT measurement is a method used to determine the level of auditory comfort level in the planning of cochlear-implanted children $[17,18]$.

Stapedius reflex reaction time is the period required for the activation of the stapedius reflex after exposing the electrical stimulus; subsequently, it indicates the velocity of stimulus movement in neural pathways. A close and inverse correlation has been addressed between reaction time, as an indicator of the speed of information processing and individual cognition capabilities [19]. More rapid stimuli moving and faster processing of auditory information is a sign of the health of the neural pathway $[11,19]$.

The stapedius reflex arc pathway involves part of the ventral and dorsal auditory stream; thus, examining the relationship between its parameters and auditory perception in children with CI can provide useful information. Such data could help with predicting their usefulness, the proper programming of the device, and selecting appropriate rehabilitation programs to improve their auditory skills. This study aimed at investigating the electrical stapedius reflex reaction time of various electrodes in the $\mathrm{CI}$ electrode array. We also aimed to examine its relationship with the scores of auditory perception skills in cochlearimplanted children.

\section{Methods}

This study was performed in two Iranian cochlear implantation centers (Rasoul Akram \& Amir Aalam Hospitals). Twenty unilateral cochlear-implanted children, aged 3-7 years, were selected based on the study's inclusion criteria. The inclusion criteria were as follows: 12 girls (Mean \pm SD age: $5.27 \pm 0.97 \mathrm{y}$ ) and 8 boys (Mean \pm SD age: $4.59 \pm 1.08 \mathrm{y}$ ). The age of receiving CI varied between 11 and 44 months in the study subjects. They used no hearing aid in the non-implanted ear. The demographic information of all study participants is presented in Table 1. All explored patients underwent a single programming protocol of speech processing and the formal auditory-verbal program. The cause of hearing deficit in all investigated patients was congenital hearing loss, without any syndromic symptoms.

The inclusion criteria also included the absence of additional disabilities and history of head trauma, no delay in motor and behavioral development, seizure, and other neurological disorders, and no use of sedative medications and other drugs affecting the stapedius reflex arc. Also, normal function of the middle ear (by using tympanometry) and the normal results of otoscopy were the inclusion criteria for the study. A written informed consent form was received from the parents of all explored subjects.

This research was approved by the Ethics Committee of the University of Social Welfare and Rehabilitation (IR.USWR.REC.1396.422). Implantation for all study participants in this study was made by a CI24R (CA)Nucleus 24 Contour Advance and all of the electrodes were active. A total of $9(45 \%)$ patients used the CP810 
Table 1. Demographic data of the study participants

\begin{tabular}{|c|c|c|c|c|c|c|c|c|}
\hline \multirow{2}{*}{ Patient } & \multirow{2}{*}{ Gender } & \multirow[b]{2}{*}{ Etiology } & \multirow[b]{2}{*}{ Ear } & \multirow{2}{*}{$\begin{array}{l}\text { Type of } \\
\text { Implant }\end{array}$} & \multirow{2}{*}{$\begin{array}{l}\text { Type of Sound } \\
\text { Processor }\end{array}$} & \multicolumn{2}{|c|}{ Age (y) } & \multirow{2}{*}{$\begin{array}{c}\text { Duration of } \\
\text { Using } \mathrm{Cl}\end{array}$} \\
\hline & & & & & & $\begin{array}{l}\text { At Cochlear } \\
\text { Implantation }\end{array}$ & At Testing & \\
\hline 1 & $\mathrm{~F}$ & Congenital & $\mathrm{R}$ & C1512 & CP910 & 44 & 72 & 28 \\
\hline 2 & $M$ & Congenital & $\mathrm{R}$ & C1512 & CP810 & 13 & 67 & 54 \\
\hline 3 & $M$ & Congenital & $\mathrm{R}$ & C1512 & CP810 & 13 & 48 & 35 \\
\hline 4 & $M$ & Congenital & $\mathrm{R}$ & C1512 & CP910 & 36 & 66 & 30 \\
\hline 5 & $\mathrm{~F}$ & Congenital & $\mathrm{R}$ & C1512 & CP910 & 24 & 60 & 36 \\
\hline 6 & $\mathrm{~F}$ & Congenital & $\mathrm{R}$ & C1512 & CP810 & 24 & 72 & 48 \\
\hline 7 & $\mathrm{~F}$ & Congenital & $\mathrm{R}$ & C1512 & CP910 & 27 & 50 & 23 \\
\hline 8 & $\mathrm{~F}$ & Congenital & $\mathrm{R}$ & C1512 & CP910 & 36 & 77 & 41 \\
\hline 9 & $M$ & Congenital & $\mathrm{R}$ & C1512 & CP910 & 15 & 48 & 33 \\
\hline 10 & $\mathrm{~F}$ & Congenital & $\mathrm{R}$ & C1512 & CP910 & 46 & 72 & 26 \\
\hline 11 & $M$ & Congenital & $\mathrm{R}$ & C1512 & CP910 & 18 & 36 & 18 \\
\hline 12 & $M$ & Congenital & $\mathrm{R}$ & C1512 & CP810 & 16 & 72 & 56 \\
\hline 13 & $\mathrm{~F}$ & Congenital & $\mathrm{R}$ & C1512 & CP810 & 11 & 40 & 29 \\
\hline 14 & $F$ & Congenital & $\mathrm{R}$ & C1512 & CP810 & 30 & 78 & 48 \\
\hline 15 & $\mathrm{~F}$ & Congenital & $\mathrm{R}$ & C1512 & CP910 & 26 & 63 & 37 \\
\hline 16 & $M$ & Congenital & $\mathrm{R}$ & C1512 & CP810 & 20 & 48 & 28 \\
\hline 17 & $\mathrm{~F}$ & Congenital & $\mathrm{R}$ & C1512 & CP810 & 11 & 53 & 42 \\
\hline 18 & $M$ & Congenital & $\mathrm{R}$ & C1512 & CP810 & 11 & 53 & 42 \\
\hline 19 & $\mathrm{~F}$ & Congenital & $\mathrm{R}$ & C1512 & CP910 & 16 & 60 & 44 \\
\hline 20 & $\mathrm{~F}$ & Congenital & $\mathrm{R}$ & C1512 & CP910 & 28 & 62 & 34 \\
\hline
\end{tabular}

Mranian Rehabilitation Journal

and 11(55\%) subjects used CP910. The programming parameters were the same for all explored children (pulse width: $25 \mu \mathrm{s}$, strategy: ACE, maxima: 8, rate: 900 pps/sec., volume: 6 , sensitivity: 10).

After completing the relevant medical history form and performing otoscopy (to check for any ear disease and other contraindication for middle ear impedance measures) and tympanometry (to confirm normal middle ear pressure), the ESR reaction time and the scores of auditory perception skills were assessed using the Categories of Auditory Performance (CAP II) test in the study children.
ESRT reaction time measurement was conducted as follows: Initially, the patient's speech processor was connected to the programming software (EP 4.4) and the coil was placed on the patient's head. Next, the impedance of the electrodes in the cochlea was measured to determine the accuracy of their performance. The NRT threshold was then obtained to estimate the point of starting stimulation in the ESRT test in apex (20-22), middle (9-11), and basal (3-1) electrodes. ESRT measurements were made by the reflex decay mode of the tympanometry device using $226 \mathrm{~Hz}$ tone probes. It was only conducted for patients with normal middle ear pressure ( -100 to +50 dapa). The tympanometry probe was placed into the non-implanted ear and was recorded in 


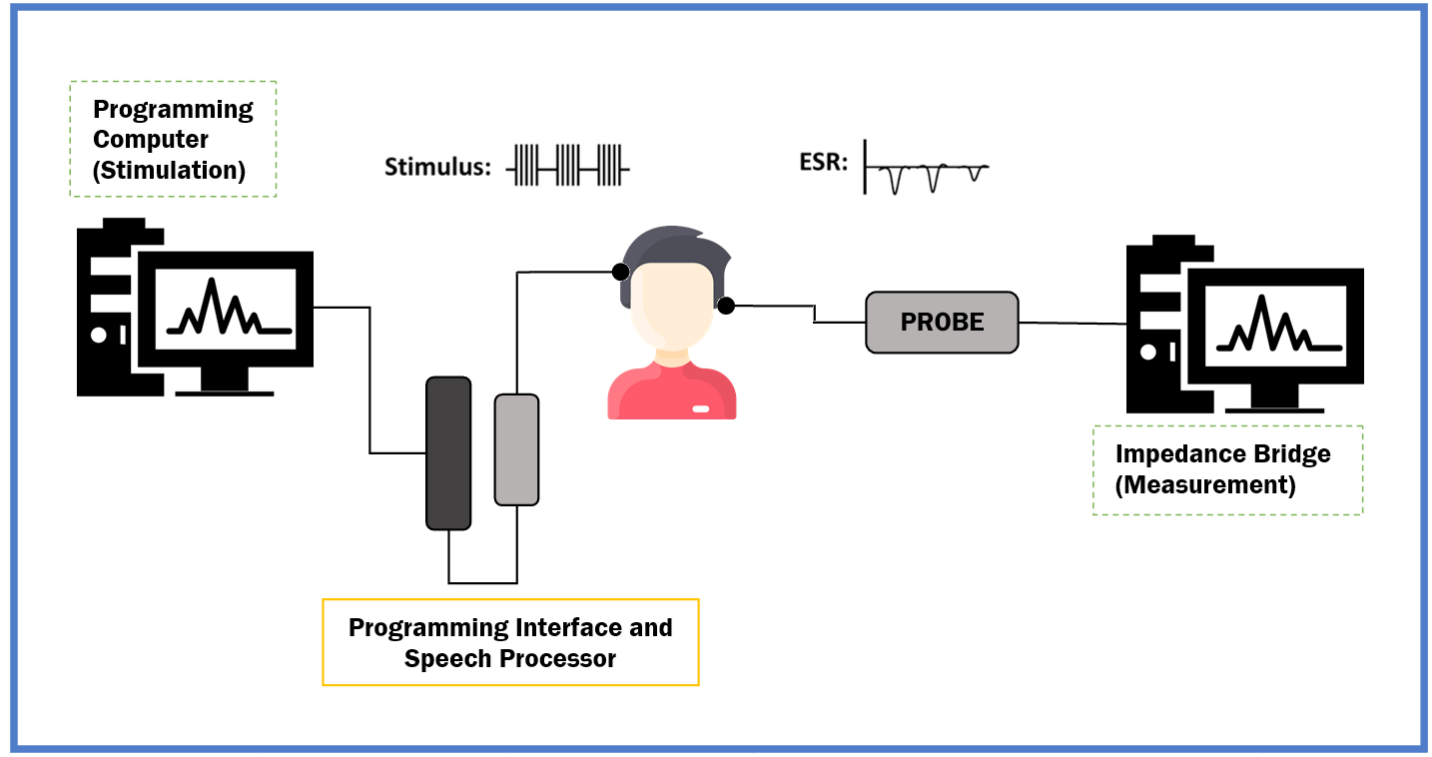

Figure 1. ESRT measurement setup

Iranian Rehabilitation Dourna

a contralateral mod; response to the electrical stimulation in the cochlear-implanted ear could be recorded [12] (Figure 1). By Nucleus Custom Sound EP.4.4TM software and selecting the ESRT measurement option, the stimulus was provided based on the threshold level determined in the NRT evaluation. The stimulus then increased in $5 \mathrm{CL}$ (Current Level) steps to record the first response (recorded deviation in the baseline). This level is the electrical stapedius reflex threshold. When there is no response, increasing in stimulation will continue until the response or discomfort level is reached. After determining the reflex threshold, to increase the amplitude of the response and to more accurately calculate reaction time, the current intensity was enhanced by $10 \mathrm{CL}$. In this study, the reaction time was equivalent to the duration of the growth of the reflex amplitude from $10 \%$ to 90\% [17] (Figure 2).

CAP Test: CAP is commonly used for assessing the auditory perception of cochlear-implanted children. The skills related to auditory perception are classified into 8 levels, from simple to difficult. This evaluation criterion is obtained through close communication with patients or their parents. The scores are calculated based on behavioral responses to all sounds, including environmental and speech sounds. They were graded on a scale of 1 to 8 as follows:

Level 1: Inability to perceive environmental sounds;

Level 2: Ability to perceive environmental sounds;

Level 3: Ability to respond to speech sounds;

Level 4: Ability to recognize environmental sounds;

Level 5: Ability to recognize some speech sounds without lip-reading;

Level 6: Ability to understand common short sentences without lip-reading;

Table 2. Means $\pm \mathrm{SD}$, maximum, and minimum values of reaction time for basal, middle, and apex electrodes

\begin{tabular}{cccc}
\hline & \multicolumn{3}{c}{ Reaction Time $(\mathrm{ms})$} \\
\cline { 2 - 4 } & Mean \pm SD & Max. & Min. \\
\hline Basal electrodes $(n=16)$ & $185.80 \pm 54.51$ & 311.50 & 97.90 \\
Middle electrodes $(n=17)$ & $196.32 \pm 69.59$ & 311.50 & 71.20 \\
Apex electrodes $(n=17)$ & $215.43 \pm 73.39$ & 369.35 & 129.05 \\
\hline
\end{tabular}




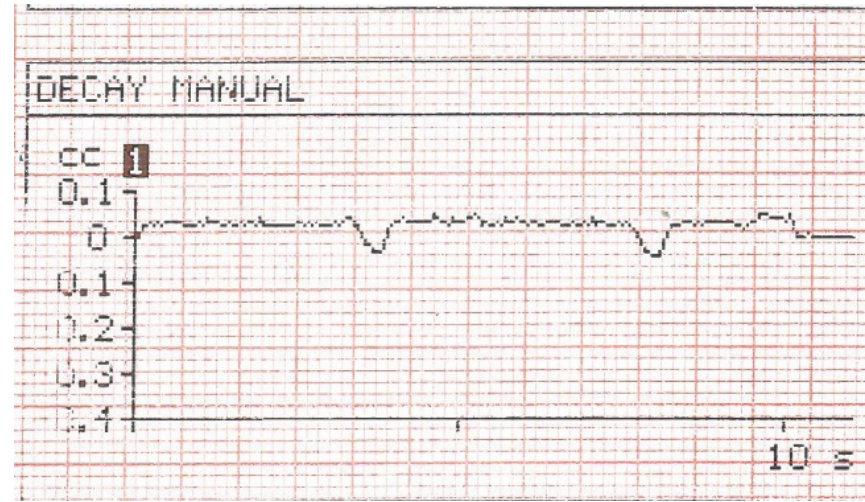

Figure 2. Electrical stapedius reflex reaction time

Level 7: Ability to communicate with people without lip-reading;

Level 8: Ability to communicate with familiar people using a phone [20].

In this study, the CAP II test was used, i.e., an upgraded version of the CAP. This version has two additional levels that address harder listening experiences; they include following a group conversation in a non-acoustic environment and telephone conversation with strangers. The minimum and maximum scores on this scale are zero and 9, respectively. On this scale, the child's assessment is based on the observations that the examiner and parents have on the child's hearing performance in various settings at the clinic, kindergarten, or home [21].

In this study, the test was performed by a single examiner, at a maximum distance of $1.5 \mathrm{~m}$ from the child, under free-field conditions and without lip-reading at a child's comfortable auditory level. In some test items in which the child failed to cooperate, the scores were recorded based on the precise answers of the parents. Data analysis was performed using SPSS v. 21 at the significance level of 0.05 for all tests. Due to the lack of normal distribution of some data, the Spearman test was used to evaluate correlations between the study variables.

\section{Results}

In this study, ESR reaction time was evaluated in the apex, middle, and basal electrodes. The average, low- est, and highest reaction times are listed in Table 2 per electrode. The results revealed that the average reaction time in the apex electrodes was higher than those in the middle and basal ones. In some electrodes, no measurable reaction time was recorded after increasing the current level to the maximum output of the device.

Table 3 outlines the mean and standard deviation scores of the CAP II in all explored children. The mean scores for each condition of the auditory perception scale are demonstrated in Table 4. Note that the lowest score concerned levels 8 and 9.

Table 5 represents the correlation between ESRT reaction time in 3 different places of the electrode and the CAP II score. As per Table 5, a significant negative correlation was observed between the reaction time of the apex electrodes and the CAP test score $(\mathrm{P}<0.05, \mathrm{r}=-0.5)$. No significant correlation was found between the reaction time of the base electrode $(\mathrm{r}=-0.06, \mathrm{P}>0.05)$ and the middle electrode $(\mathrm{r}=-0.34, \mathrm{P}>0.05)$.

\section{Discussion}

Auditory perception is a complex process; more than just transmitting sound from the ear to the brain. A significant part of the progress in acquiring auditory skills depends on the auditory pathways from the auditory nerve to the cerebral cortex and the adoption of appropriate post-operation auditory training rehabilitation. Objective electrophysiological assessments provide a more accurate examination of the pathways involved in

Table 3. Mean \pm SD, maximum, and minimum values of the CAP II in the explored cochlear-implanted children

\begin{tabular}{cccc}
\hline Variable & Mean $\pm S D$ & Max & Min \\
\hline CAP scores $(n=20)$ & $7.28 \pm 0.93$ & 8.44 & 4.76 \\
\hline
\end{tabular}


Table 4. Mean scores per the condition of the CAP II in the studied cochlear-implanted children

\begin{tabular}{|c|c|c|}
\hline Levels & Conditions & Mean \\
\hline 0 & No awareness of environmental sound & 0 \\
\hline 1 & Awareness of environmental sounds & 10 \\
\hline 2 & Responds to speech sounds. & 9.22 \\
\hline 3 & Recognizes environmental sounds. & 9.74 \\
\hline 4 & Discriminates at least two speech sounds. & 9.75 \\
\hline 5 & Understands common phrases without lip-reading. & 8.96 \\
\hline 6 & Understands conversation without lip-reading with a familiar talker. & 8.17 \\
\hline 7 & Can use the telephone with a familiar talker & 7.8 \\
\hline 8 & $\begin{array}{l}\text { Follows group conversation in a reverberant room where there is some interfering noise such as a class- } \\
\text { room or a restaurant }\end{array}$ & 5.41 \\
\hline 9 & Use of telephone with the unknown speaker in an unpredictable context & 2 \\
\hline
\end{tabular}

Iranian Rehabilitation Journal

auditory processing and a better prediction of rehabilitation outcomes. As a fast, convenient, and inexpensive evaluation, this study used assessment. ESRT examines pathways involved in auditory processing in the lower end of the brainstem. The relationship between ESR reaction time and auditory performance skills in cochlearimplanted children was examined.

The present study findings suggested that the mean ESR reaction time in the apex electrodes (low-frequency region) was greater than those in the middle electrodes (mid frequencies region) and the basal ones (high frequencies region). Studies using ESR reaction time on cochlear-implanted users are scarce. Studies that have been performed on the acoustic stapedius reflex reaction time in the healthy population indicated that increasing stimulus frequency results in a decrease in reaction time. In other words, for middle frequencies $(1500 \mathrm{~Hz})$, reaction time is shorter than that in low frequencies $(500 \mathrm{~Hz})$, i.e., consistent with the current research findings [17].
A study of EABR measurement on cochlear-implanted children revealed that responses from apical electrodes are steeper than basal electrodes and more rapid neural transmission beyond the primary auditory nerve. This effect can be attributed to differences in the density of surviving nerve elements in the cochlea and the proximity of the electrode array to the spiral ganglion cells [22]. From another viewpoint, the cause of increased latencies at the apex electrode, compared to the basal electrode can concern the electrophysiological properties of type II neurons [23].

The data presented a significant negative correlation between the reaction time of apex electrodes and the CAP II test results. Wang et al. investigated the relationship between EABR parameters (the threshold \& the latency of wave V) and the auditory performance in 40 cochlear-implanted children. Accordingly, they reported a significant negative correlation between the measurable parameters in EABR and CAP scores [24]. These findings support the hypothesis of the association between

Table 5. Spearman's correlation coefficient between the reaction time of ESRT and the CAP II scores in the basal, middle, and apical electrodes

\begin{tabular}{ccc}
\hline Variables & Correlation Coefficient $(\mathbf{r})$ & $\mathbf{P}$ \\
\hline Basal electrodes $(n=16)$ & -0.06 & 0.81 \\
Middle electrodes $(n=17)$ & -0.36 & 0.15 \\
Apex electrodes $(n=17)$ & -0.5 & $0.03^{*}$ \\
\hline
\end{tabular}


brainstem neural pathway and auditory performance in cochlear-implanted children.

Emamdjomeh et al. examined blink reflex in 85 patients with CI; they concluded that patients with blink reflex achieved higher scores in the auditory performance test. They also noted that due to the similarity of the structure of the blink reflex with the stapedius reflex arc, this reflex can be used as a substitute measurement for the stapedius reflex in those who cannot be evaluated by the stapedius reflex, e.g., patients with middle ear effusion [11]. The literature suggests that the reaction time of blink reflex, as an indicator of the speed of information processing is reversely correlated with the scores of conventional cognition tests. People with higher scores on these tests have shorter reaction times, which indicates their faster processing speed through neural pathways. The blink reflex reaction time may be changed by the affection of the higher central nervous system through relating efferent pathways [19].

This study signified an inverse correlation between the ESR reaction time and the mean scores of the CAP II scale. Likewise, children with $\mathrm{CI}$ and shorter reaction times in the apex electrodes might have more neural fibers remaining, faster transmission, and processing of the neurons; they also might have healthy neural pathways to the brainstem, leading to higher scores in the auditory performance test. Perhaps the results of the stapedius reflex reaction time can help predict the effectiveness of CI in children and in choosing a more appropriate auditory rehabilitation program for acquiring auditory skills.

\section{Conclusion}

The present study results indicated a significant inverse correlation between the electrical stapedius reflex reaction time in apex electrodes and auditory performance score in cochlear-implanted children; thus, the lower the stapedius reflex reaction time, the higher the auditory perception scores in these children.

\section{Ethical Considerations}

\section{Compliance with ethical guidelines}

The participants were informed of the purpose of the research and its implementation stages. A written consent has been obtained from the subjects. They were also assured about the confidentiality of their information and were free to leave the study whenever they wished, and if desired, the research results would be available to them. The Helsinki Convention was also observed.

\section{Funding}

This study was supported by the University of Social Welfare and Rehabilitation Sciences (IR.USWR REC.1396.422).

\section{Authors' contributions}

All authors equally contributed to preparing this article.

\section{Conflict of interest}

The authors declared no conflict of interest.

\section{Acknowledgments}

Our heartfelt thanks go to the explored children as well as their parents who patiently and sincerely participated in this research study. We also would like to thank Farzad Mobedshahi, from Amir Aalam Hospital, for his constant support during this research.

\section{References}

[1] Anderson CA, Lazard DS, Hartley DE. Plasticity in bilateral superior temporal cortex: Effects of deafness and cochlear implantation on auditory and visual speech processing. Hearing Research. 2017; 343:138-49. [DOI:10.1016/j. heares.2016.07.013] [PMID]

[2] Qiao XF, Li X, Zhang QW, Li TL, Wang D. Postoperative objective detecting techniques for cochlear implant children with inner ear malformation. International Journal of Pediatric Otorhinolaryngology. 2017; 102:1-6. [DOI:10.1016/j. ijporl.2017.08.026] [PMID]

[3] Saki N, Bayat A, Hoseinabadi R, Nikakhlagh S, Karimi M, Dashti R. Universal newborn hearing screening in southwestern Iran. International Journal of Pediatric Otorhinolaryngology. 2017; 97:89-92. [DOI:10.1016/j.ijporl.2017.03.038] [PMID]

[4] Firoozbakht M, Mahmoudian S, Alaeddini F, Esmaeilzadeh M, Rafiei M, Firouzbakht A, et al. Community-based newborn hearing screening programme for early detection of permanent hearing loss in Iran: An eight-year cross-sectional study from 2005 to 2012. Journal of Medical Screening. 2014; 21(1):10-7. [DOI:10.1177/0969141314522992] [PMID]

[5] Truy E, Gallego S, Chanal JM, Collet L, Morgon A. Correlation between electrical auditory brainstem response and perceptual thresholds in digisonic Cochlear implant users. The Laryngoscope.1998;108(4Pt1):554-9. [DOI:10.1097/00005537199804000-00017] [PMID]

[6] Alfelasi M, Piron JP, Mathiolon C, Lenel N, Mondain M, Uziel A, et al. The transtympanic promontory stimulation test in patients with auditory deprivation: Correlations with electrical dynamics of cochlear implant and speech percep- 
tion. European Archives of Oto-Rhino-Laryngology. 2013; 270(6):1809-15. [DOI:10.1007/s00405-012-2125-1] [PMID]

[7] Asal S, Sobhy OA, Nooman M. The relationship between the electrical stapedial muscle reflex threshold and electrical and behavioral measures in cochlear implant patients. The Egyptian Journal of Otolaryngology. 2016; 32(1):49-52. [DOI:10.4103/1012-5574.175848]

[8] Pickles JO. An introduction to the physiology of hearing. Massachusetts: Academic Press; 1982. https://www.google. com/books/edition/An_Introduction_to_the_Physiology_ of_Hea/januAAAAMAAJ?hl=en

[9] Hunter LL, Shahnaz N. Acoustic immittance measures: Basic and advanced practice. San Diego: Plural Publishing, Inc.; 2013. https://www.google.com/books/edition/Acoustic Immittance_Measures/YVg0BwAAQBAJ?hl=en\&gbpv=1

[10] Norris TW, Stelmachowicz PG, Taylor DJ. Acoustic reflex relaxation to identify sensorineural hearing impairment. Archives of Otolaryngology. 1974; 99(3):194-7. [DOI:10.1001/ archotol.1974.00780030202009] [PMID]

[11] Emamdjomeh H, Shafaghat L, Abbassalipour P, Hassanzadeh S, Alaeddini F, Farhadi M, et al. Blink reflex and auditory speech perception in prelingually cochlear-implanted children. Acta Oto-Laryngologica. 2005; 125(4):358-62. [DOI:10.1067/mhn.2002.125110] [PMID]

[12] Cooper H, Craddock LC. Cochlear implants: A practical guide. New Jersey: John Wiley \& Sons; 2006. https://www. google.com/books/edition/Cochlear_Implants/j9FhJoFPW$0 \mathrm{C} ? \mathrm{hl}=\mathrm{en} \& \mathrm{gbpv}=1$

[13] Greisiger R, Shallop JK, Hol PK, Elle OJ, Jablonski GE. Cochlear implantees: Analysis of behavioral and objective measures for a clinical population of various age groups. Cochlear Implants International. 2015; 16 (suppl 4):1-19. [DOI:10.1080/14670100.2015.1110372] [PMID]

[14] Katz J, Medwetsky L, Hood LJ, Burkard R. Handbook of clinical audiology. Philadelphia: Wolters Kluwer Health/ Lippincott Williams \& Wilkins; 2009. https://www.google. com/books/edition/Handbook_of_Clinical_Audiology/ OsfWPAAACAAJ?hl=en Lippincott William \& Wilkins; 2009.

[15] Pau HW, Ehrt K, Just T, Sievert U, Dahl R. How reliable is visual assessment of the electrically elicited stapedius reflex threshold during cochlear implant surgery, compared with tympanometry? The Journal of laryngology and Otology. 2011; 125(3):271-3. [DOI:10.1017/S0022215110002392] [PMID]

[16] Jerger J, Oliver TA, Chmiel RA. Prediction of dynamic range from stapedius reflex in cochlear implant patients. Ear and Hearing. 1988; 9(1):4-8. [DOI:10.1097/00003446198802000-00010] [PMID]

[17] Reena N. Characterization of acoustic reflex latency in females. Global Journal of Otolaryngology. 2017; 11(2):555808 [DOI:10.19080/GJO.2017.11.555808]

[18] Clement RS, Carter PM, Kipke DR. Measuring the electrical stapedius reflex with stapedius muscle electromyogram recordings. Annals of Biomedical Engineering. 2002; 30(2):169-79. [DOI:10.1114/1.1454132] [PMID]

[19] Smyth M, Anderson M, Hammond G. The modified blink reflex and individual differences in speed of processing. Intelligence. 1999; 27(1):13-35. [DOI:10.1016/S0160-2896(99)00012-4]
[20] Archbold S, Lutman ME , Marshall DH. Categories of auditory performance. The Annals of Otology, Rhinology \& Laryngology. Supplement. 1995; 166:312-4. [PMID]

[21] Gilmour L. The inter-rater reliability of categories of auditory performance-II (CAP)-II [MSc. thesis]. Southampton: University of Southampton; 2010. https://eprints.soton. ac.uk/173775/

[22] Abdelsalam NM, Afifi PO. Electric auditory brainstem response (E-ABR) in cochlear implant children: Effect of age at implantation and duration of implant use. Egyptian Journal of Ear, Nose, Throat and Allied Sciences. 2015; 16(2):145-50. [DOI:10.1016/j.ejenta.2015.03.001]

[23] Joly CA, Péan V, Hermann R, Seldran F, Thai-Van H, Truy E. Using electrically-evoked compound action potentials to estimate perceptive levels in experienced adult cochlear implant users. Otology \& Neurotology. 2017; 38(9):1278-89. [DOI:10.1097/MAO.0000000000001548] [PMID]

[24] Wang Y, Pan T, Deshpande SB, Ma F. The relationship between EABR and auditory performance and speech intelligibility outcomes in pediatric cochlear implant recipients. American Journal of Audiology. 2015; 24(2):226-34 [DOI:10.1044/2015_AJA-14-0023] [PMID] 
This Page Intentionally Left Blank 